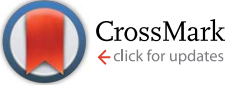

Cite this: RSC Adv., 2017, 7, 8832
Received 9th December 2016 Accepted 20th January 2017

DOI: $10.1039 / c 6 r a 27989 a$

rsc.li/rsc-advances

\section{Dipolar vinyl sulfur fluorescent dyes. Synthesis and photophysics of sulfide, sulfoxide and sulfone based $D-\pi-A$ compounds $\uparrow$}

\author{
Matias Monçalves, ${ }^{a}$ Gabriel M. Zanotto, ${ }^{d}$ Josene M. Toldo, ${ }^{d}$ Daniel S. Rampon, ${ }^{c}$ \\ Paulo H. Schneider, ${ }^{b}$ Paulo F. B. Gonçalves, ${ }^{d}$ Fabiano S. Rodembusch*b \\ and Claudio C. Silveira*a
}

New vinyl sulfides and sulfoxides were obtained in good yields using the Horner-Wadsworth-Emmons (HWE) reaction. The vinyl sulfides and sulfoxides presented preferentially the E-stereochemistry. The respective vinyl sulfones were obtained in good yields from the vinyl sulfides by a simple oxidation step using $m C P B A$, solely as the $E$ isomers. These derivatives presented absorption maxima in the UV-A region with molar absorptivity coefficients and radiative rate constant values ascribed to spin and symmetry-allowed ${ }^{1} \pi-\pi^{*}$ electronic transitions. Experimentally, a small solvatochromic effect indicated an almost absent charge transfer character in the ground-state. A fluorescence emission in the violetgreen region with a significative redshift on the maxima with increasing solvent polarity was observed, which could be related to a better electron delocalization in the excited state, as a result of an intramolecular charge transfer state. DFT and TD-DFT calculations were performed at the PBE1PBE and CAM-B3LYP levels of theory. No solvatochromic effect was observed in the ground state, but a bathochromic effect was detected in the emission maxima. Starting from sulfides to sulfones, the addition of oxygen atoms improved the charge separation, enabling an ICT state, mainly in P3 and P5. This charge separation was more efficient in the triphenylamino derivatives than among the pyrene derivatives since the first one has a better electron-donating character.

\section{Introduction}

High-efficiency organic luminescent materials are critically important in a variety of high-tech innovations. ${ }^{\mathbf{1 - 5}}$ Due to the rapid growth of this field, the development of novel and efficient emitters is a very important task. In the past few decades, pushpull structures composed of a $\pi$-conjugated core substituted by electron-donating (D) and electron-attracting (A) (D- $\pi-A)$ groups have been extensively studied in materials chemistry. ${ }^{\mathbf{6}-11}$ These molecular systems have also been extended to

\footnotetext{
${ }^{a}$ Departamento de Quimica, Universidade Federal de Santa Maria, CEP 97105-900, Santa Maria-RS, Brazil. E-mail: silveira@quimica.ufsm.br; Fax: +55 55 3220-8754

${ }^{b}$ Grupo de Pesquisa em Fotoquímica Orgânica Aplicada, Universidade Federal do Rio Grande do Sul - Instituto de Química, Avenida Bento Gonçalves 9500. CEP 91501970, Porto Alegre-RS, Brazil. E-mail: fabiano.rodembusch@ufrgs.br; Fax: +55 51 3308 7304; Tel: +55 5133087204

'Universidade Federal do Paraná, Departamento de Química, Laboratório de Polímeros e Catálise, CEP 81531-980, Curitiba, PR, Brazil

${ }^{d}$ Grupo de Química Teórica, Universidade Federal do Rio Grande do Sul - Instituto de Química, Avenida Bento Gonçalves, 9500, CP 15003, CEP 91501-970, Porto Alegre-RS, Brazil

$\dagger$ Electronic supplementary information (ESI) available: Spectroscopic characterization of the compounds and additional results of the theoretical calculations. See DOI: 10.1039/c6ra27989a
}

quadrupolar (D- $-\pi-\mathrm{A}-\pi-\mathrm{D}$ or $\mathrm{A}-\pi-\mathrm{D}-\pi-\mathrm{A})$ compounds, which also have promising technological applications. ${ }^{\mathbf{1 2 - 1 7}}$ In general, optical materials take important roles in optoelectronics, as part of transistors, OLEDs, solar cells, lightening agents and light modulators. ${ }^{18,19}$ These usual $\mathrm{D}-\pi-\mathrm{A}$ molecular architectures play an important role in their photophysics because they not only show high fluorescent quantum yields owing to the effective radiative decay of their excited intramolecular chargetransfer (ICT) state but also possess impressive bipolar chargetransporting properties for their constitutive hole- and electrontransporting moieties, ${ }^{20-25}$ that can be modulated through tuning the groups electron donor and/or acceptor strengths. ${ }^{\mathbf{2 6 - 3 0}}$ Concerning those functional groups, the organosulfides allow a tuneable electronic behavior that can be easily modulated through a single step oxidation to the respective sulfoxides or sulfones, which are effective electron acceptor groups. ${ }^{31-38}$

In this regard, our continuous interests in the synthesis of organochalcogen compounds prompted us to access symmetrical and unsymmetrical vinyl sulfides by a straightforward approach, using a Wittig-Horner reaction, as precursors of products carrying a higher oxidation state on sulfur. ${ }^{39,40}$ In this sense, photoactive divinyl sulfides and sulfones have been obtained. ${ }^{\mathbf{3 1 4 1}}$

However, there is a lack of information on the rationalization of comparative electronic effects exerted by organosulfides, 
sulfoxides and sulfones on excited and ground states of pushpull $\pi$-conjugated structures. Therefore, herein we describe the synthesis of novel vinyl sulfides, sulfoxides and sulfones containing pyrene and triphenylamine as end-capped electron donor groups. In addition, the electronic, photophysical and theoretical properties of these compounds were extensively explored, and the effect of the oxidation state of the sulfur on the electronic properties of push-pull molecular systems were evaluated, comparing the experimental results with the theoretical properties, predicted with TD-DFT calculations.

\section{Experimental}

\section{General information}

All reactions were performed in flame-dried glassware under ambient conditions unless otherwise stated. All solvents were purified according to the literature and transferred via syringe. ${ }^{42}$ Tetrahydrofuran (THF) was refluxed under Na/benzophenone and distilled immediately before use. Unless otherwise stated, commercial reagents were used without additional purification. The column chromatographic purification of the products was performed on silica gel (230-400 mesh). The thin-layer chromatography (TLC) plates were visualized by exposure to UV radiation $(365 \mathrm{~nm})$, iodine vapours and/or acid solution of vanillin.

The ${ }^{1} \mathrm{H}$ NMR spectra were recorded at $200 / 400 \mathrm{MHz}$ and the ${ }^{13} \mathrm{C}$ NMR spectra were measured at $50 / 100 \mathrm{MHz}$, in $\mathrm{CDCl}_{3}$ as solvent with TMS as reference. Coupling constants $(J)$ are reported in Hertz. Abbreviations to denote the multiplicity of a particular signal are s (singlet), d (doublet), dd (doublet of doublets), $\mathrm{t}$ (triplet) and $\mathrm{m}$ (multiplet). A Perkin-Elmer CHN 2400 analyzer was used for elemental analyses. The infrared spectra were recorded on a FTIR spectrometer, with the samples dispersed in $\mathrm{KBr}$ pellets. The UV-Vis absorption spectra were recorded on a Shimadzu UV-2450 spectrophotometer in a concentration range of $10^{-4}$ to $10^{-5} \mathrm{M}$. The steady state fluorescence spectra were measured using a Shimadzu RF5301PC spectrofluorometer. The maximum absorption wavelength was used as excitation wavelength for fluorescence measurements. The quantum yield of fluorescence $\left(\Phi_{\mathrm{FL}}\right)$ was determined by applying the dilute optical method. Quinine sulphate $(\mathrm{QS})$ in $\mathrm{H}_{2} \mathrm{SO}_{4}\left(0.5 \mathrm{~mol} \mathrm{~L}^{-1}\right)\left(\Phi_{\mathrm{FL}}=0.55\right)$ was used as the quantum yield standard. ${ }^{43}$ All measurements were performed at room temperature $\left(25^{\circ} \mathrm{C}\right)$.

\section{Theoretical calculations}

In parallel to the experimental studies, theoretical calculations were carried out using the Gaussian 09 package ${ }^{44}$ for molecules P1-P6. For geometry optimizations and vibrational analysis in the ground state, the Density Functional Theory (DFT) was used with two hybrid exchange-correlation functionals: PBE1PBE, a global hybrid parameter free with $25 \%$ exact exchange functiona $^{45}$ and CAM-B3LYP, the long range corrected version of B3LYP using the Coulomb-attenuating method, ${ }^{46}$ both with the cc-pVDZ basis set. These functionals were chosen for this study since they have presented good results and have been extensively tested in different systems for a large range of properties, particularly for absorption and emission spectral simulations and electronic properties. ${ }^{47-50}$ However, in systems where it is possible to observe charge transfer, it is recommended to use the range-separated hybrid functionals, like the CAM-B3LYP. ${ }^{48,50}$ Geometry optimizations and vibrational analysis on the first excited state were performed using TD-DFT (Time Dependent Density Functional Theory) with the ccpVDZ basis set. Population analysis and vertical transitions were performed using jun-cc-pVTZ basis sets. The jun-basis set, named calendar basis set, is recommended by Truhlar et al. ${ }^{51}$ as a better option to the default augmented (aug) basis sets, showing a lower computational cost. These basis sets are constructed by removing diffuse functions from the augmented (aug-) basis sets. The jun-cc-pV*Z basis sets remove the diffuse function from $\mathrm{H}$ and $\mathrm{He}$ and also remove the highest angular momentum diffuse function from all other atoms. All equilibrium geometries were characterized by the absence of imaginary frequencies. The influence of the solvent was considered in all calculations (geometry optimization and vertical transitions) using PCM (Polarizable Continuum Model) ${ }^{52}$ and the solvents used were 1,4-dioxane, dichloromethane, acetonitrile and ethanol. Charges from electrostatic potential using a grid based method (ChelpG) were used to obtain the electrostatic potential surface and dipole momenta. All images of the geometry and molecular orbital were generated using the ChemCraft program. ${ }^{53}$

\section{Synthesis}

Diethyl phenylthiomethylphosphonate (1). To a cooled $\left(0^{\circ} \mathrm{C}\right)$ solution of $\mathrm{NaOH}(0.84 \mathrm{~g}, 21 \mathrm{mmol})$ in dry ethanol $(100 \mathrm{~mL})$ was added dropwise via syringe benzenethiol $(2.31 \mathrm{~g}, 21 \mathrm{mmol})$. The mixture was stirred for $30 \mathrm{~min}$ at $0{ }^{\circ} \mathrm{C}$. Diethyl tosylmethyl phosphonate $(6.44 \mathrm{~g}, 20 \mathrm{mmol})$ was added and the mixture was stirred for $24 \mathrm{~h}$ at room temperature. The mixture was extracted with EtOAc $(3 \times 50 \mathrm{~mL})$ and $\mathrm{H}_{2} \mathrm{O}(150 \mathrm{~mL})$ and the combined organic layers were washed with saturated aqueous $\mathrm{NH}_{4} \mathrm{Cl}$, dried over $\mathrm{MgSO}_{4}$, filtered and concentrated under reduced pressure. Purification by flash column chromatography (silica gel, using $5: 95$ to $50: 50, \mathrm{v} / \mathrm{v}$, EtOAc/hexanes) gave the product as a colourless oil $(4.68 \mathrm{~g}, 90 \%) .{ }^{1} \mathrm{H}$ NMR $\left(200 \mathrm{MHz}, \mathrm{CDCl}_{3}\right)$ $\delta(\mathrm{ppm}): 7.47-7.42(\mathrm{~m}, 2 \mathrm{H}), 7.33-7.21(\mathrm{~m}, 3 \mathrm{H}), 4.21-4.06(\mathrm{~m}$, $4 \mathrm{H}), 3.24(\mathrm{~d}, J=14.0 \mathrm{~Hz}, 2 \mathrm{H}), 1.32(\mathrm{t}, 6 \mathrm{H})$.

4-(Diphenylamino)benzaldehyde (2). This compound was synthesized according to the literature.$^{38} \mathrm{~A}$ dry $50 \mathrm{~mL}$ twonecked flask was equipped with a reflux condenser under a positive argon pressure and cooled with an ice-water bath. The flask was charged with dry DMF $(3 \mathrm{~mL}, 39 \mathrm{mmol})$ and $\mathrm{POCl}_{3}(2.3$ $\mathrm{mL}, 25 \mathrm{mmol}$ ) was then added dropwise. After that, triphenylamine $(1.2 \mathrm{~g}, 5 \mathrm{mmol})$ in 1,2-dichloroethane $(10 \mathrm{~mL})$ was added dropwise and the reaction was heated to $45{ }^{\circ} \mathrm{C}$ for $5 \mathrm{~h}$. After cooling, the mixture was poured on an ice-bath with stirring and neutralized with $\mathrm{Na}_{2} \mathrm{CO}_{3}$. A pale yellow solid was collected by filtering and recrystallized in ethanol to give $2(1.12 \mathrm{~g}, 82 \%) .{ }^{1} \mathrm{H}$ NMR (400 MHz, $\left.\mathrm{CDCl}_{3}\right) \delta(\mathrm{ppm}): 9.80(\mathrm{~s}, 1 \mathrm{H}), 7.68(\mathrm{~d}, 2 \mathrm{H}), 7.36-$ $7.32(\mathrm{t}, 4 \mathrm{H}), 7.19-7.15(\mathrm{~m}, 6 \mathrm{H}), 7.02(\mathrm{~d}, 2 \mathrm{H})$. 
Diethyl ((phenylsulfinyl)methyl)phosphonate (4). This compound was synthesized according to the literature. ${ }^{54} \mathrm{NaIO}_{4}$ $(1.302 \mathrm{~g}, 6.09 \mathrm{mmol})$ was dissolved in a $1: 2$ mixture of $\mathrm{THF} /$ $\mathrm{H}_{2} \mathrm{O}(15 \mathrm{~mL})$ and cooled to $0{ }^{\circ} \mathrm{C}$. A solution of $1(1.507 \mathrm{~g}, 5.79$ $\mathrm{mmol})$ in THF $(5 \mathrm{~mL})$ was added dropwise. The mixture was stirred at room temperature for $93 \mathrm{~h}$. The solvent was removed under reduced pressure and the resulting crude mixture was diluted with EtOAc, washed with saturated aqueous $\mathrm{NH}_{4} \mathrm{Cl}$, dried over $\mathrm{MgSO}_{4}$ and concentrated under vacuum. The crude product was purified by flash chromatography (EtOAc/hexanes, $7: 3, \mathrm{v} / \mathrm{v})$ to yield $4(1.03 \mathrm{~g}, 65 \%)$ as a light yellow oil. ${ }^{1} \mathrm{H}$ NMR $\left(200 \mathrm{MHz}, \mathrm{CDCl}_{3}\right) \delta(\mathrm{ppm}): 7.77-7.65(\mathrm{~m}, 2 \mathrm{H}), 7.60-7.51(\mathrm{~m}, 3 \mathrm{H})$, 4.25-4.03 (m, 4H), 3.50-3.22 (m, 2H), 1.36-1.21 (m, 6H).

General procedure for the preparation of the vinyl sulfides. Under an argon atmosphere, a dry $50 \mathrm{~mL}$ two-necked flask was charged with diethyl phenylthiomethylphosphonate $(\mathbf{1}, 0.911 \mathrm{~g}$, $3.5 \mathrm{mmol})$ and THF (30 mL) at room temperature. $\mathrm{NaH}(60 \%$ in mineral oil; $0.139 \mathrm{~g}, 3.5 \mathrm{mmol}$ ) was added to the solution and stirred for $15 \mathrm{~min}$. After this time, the appropriate carbonyl compound ( $3 \mathrm{mmol}$ ) was added and the reaction was stirred for approximately $24 \mathrm{~h}$ at $60{ }^{\circ} \mathrm{C}$ (oil bath temperature). The system was cooled to room temperature, a saturated aqueous $\mathrm{NH}_{4} \mathrm{Cl}$ solution $(20 \mathrm{~mL})$ was added, the mixture was extracted with $\mathrm{CH}_{2} \mathrm{Cl}_{2}(2 \times 20 \mathrm{~mL})$, and the organic layer was dried over $\mathrm{MgSO}_{4}$, filtered and concentrated under reduced pressure. The residue was purified by column chromatography, eluting with ethyl acetate/hexanes $(1: 9, \mathrm{v} / \mathrm{v})$.

$\boldsymbol{N}, \boldsymbol{N}$-Diphenyl-4-(2-(phenylthio)vinyl)aniline (P1). Pale yellow solid. Yield: $1.058 \mathrm{~g}$ (93\%). Mp: $126{ }^{\circ} \mathrm{C} . E / Z: 6 / 1 .{ }^{1} \mathrm{H}$ NMR (400 $\left.\mathrm{MHz}, \mathrm{CDCl}_{3}, \mathrm{TMS}\right) E / Z$ isomers $\delta$ (ppm): 7.52-7.43 (m, 2H), 7.40-7.25 (m, 9H), 7.18-7.04 (m, 8H), 6.81 (d, J=15.4 Hz, 1H, E), $6.76(\mathrm{~d}, J=15.4 \mathrm{~Hz}, 1 \mathrm{H}, E), 6.58(\mathrm{~d}, J=10.7 \mathrm{~Hz}, 1 \mathrm{H}, Z), 6.44(\mathrm{~d}, J$ $=10.7 \mathrm{~Hz}, 1 \mathrm{H}, Z) .{ }^{13} \mathrm{C} \mathrm{NMR}\left(100 \mathrm{MHz}, \mathrm{CDCl}_{3}, \mathrm{TMS}\right) \delta(\mathrm{ppm})$ : 120.9, 123.1, 123.2, 123.5, 124.6, 124.6, 126.7, 127.0, 129.1, $129.3,129.5,129.8,129.9,130.7,132.5,135.9,147.6$. FTIR $(\nu /$ $\mathrm{cm}^{-1}$ ): 3417, 3016, 1589, 1489, 1327, 1280, 1072, 740, 686, 640. Anal. calcd for $\mathrm{C}_{26} \mathrm{H}_{21} \mathrm{NS}$ : C, 82.28; H, 5.58; N, 3.69. Found: C, 82.18; H, 5.35; N, 3.24.

Phenyl(2-(pyren-1-yl)vinyl)sulfane (P2). Pale yellow solid. Yield: $0.898 \mathrm{~g}$ (89\%). Mp: $112{ }^{\circ} \mathrm{C} . E / Z: 5 / 1 .{ }^{1} \mathrm{H}$ NMR $(400 \mathrm{MHz}$, $\mathrm{CDCl}_{3}$, TMS) $E / Z$ isomers $\delta$ (ppm): 8.23-8.19 (m, $\left.1 \mathrm{H}\right), 8.13-7.89$ $(\mathrm{m}, 7 \mathrm{H}), 7.70(\mathrm{~d}, J=15.2 \mathrm{~Hz}, 1 \mathrm{H}, E), 7.51-7.40(\mathrm{~m}, 2 \mathrm{H}), 7.36-7.18$ $(\mathrm{m}, 3 \mathrm{H}), 7.07$ (d, $J=15.2 \mathrm{~Hz}, 1 \mathrm{H}, E), 6.81$ (d, $J=10.4 \mathrm{~Hz}, 1 \mathrm{H}, Z)$. ${ }^{13} \mathrm{C}$ NMR (100 MHz, $\mathrm{CDCl}_{3}$, TMS) $\delta$ (ppm): 122.9, 123.6, 124.5, $124.9,125.0$, 125.1, 125.3, 126.0, 126.6, 127.2, 127.3, 127.4, $127.7,127.8,128.7,129.2,129.3,130.0,130.1,130.9,130.9$, 131.1, 131.6, 135.3. FTIR $\left(\nu / \mathrm{cm}^{-1}\right): 3471,3425,3016,1573,1473$, 1087, 941, 840, 740, 694. Anal. calcd for $\mathrm{C}_{24} \mathrm{H}_{16} \mathrm{~S}: \mathrm{C}, 85.68 ; \mathrm{H}$, 4.79. Found: C, 85.28; H, 4.57.

General procedure for the preparation of the vinyl sulfoxides. To a dry $50 \mathrm{~mL}$ two-necked flask, under argon atmosphere, was added diethyl ((phenylsulfinyl)methyl)phosphonate (4, $0.54 \mathrm{~g}, 1.95 \mathrm{mmol})$ and THF (15 mL) at room temperature. $\mathrm{NaH}$ (60\% in mineral oil; $0.078 \mathrm{~g}, 1.95 \mathrm{mmol}$ ) was added to solution and stirred for $15 \mathrm{~min}$. After this time, the appropriate carbonyl compound $(1.67 \mathrm{mmol})$ was added and the reaction was stirred for approximately $24 \mathrm{~h}$ at $60{ }^{\circ} \mathrm{C}$ (oil bath temperature). The system was cooled to room temperature and saturated aqueous $\mathrm{NH}_{4} \mathrm{Cl}$ solution $(20 \mathrm{~mL})$ was added; the mixture was extracted with $\mathrm{CH}_{2} \mathrm{Cl}_{2}(2 \times 20 \mathrm{~mL})$, the organic layer was dried over $\mathrm{MgSO}_{4}$, filtered and concentrated under reduced pressure. The residue was purified by column chromatography, eluting with ethyl acetate/hexanes $(1: 9, \mathrm{v} / \mathrm{v})$.

$\boldsymbol{N}, \boldsymbol{N}$-Diphenyl-4-(2-(phenylsulfinyl)vinyl)aniline (P3). Yellow solid. Yield: $0.579 \mathrm{~g}$ (71\%). Mp: $44{ }^{\circ} \mathrm{C} . E / Z: 7 / 1 .{ }^{1} \mathrm{H}$ NMR (400 $\left.\mathrm{MHz}, \mathrm{CDCl}_{3}, \mathrm{TMS}\right) E / Z$ isomers $\delta(\mathrm{ppm}): 7.69-7.65(\mathrm{~m}, 2 \mathrm{H})$, $7.52-7.44(\mathrm{~m}, 3 \mathrm{H}), 7.15-6.96(\mathrm{~m}, 8 \mathrm{H}), 6.67(\mathrm{~d}, J=15.5 \mathrm{~Hz}, 1 \mathrm{H}, E)$, 6.29 (d, $J=10.6 \mathrm{~Hz}, 1 \mathrm{H}, Z) .{ }^{13} \mathrm{C} \mathrm{NMR}\left(100 \mathrm{MHz}, \mathrm{CDCl}_{3}, \mathrm{TMS}\right)$ $\delta$ (ppm): 121.2, 124.0, 124.4, 125.0, 125.6, 127.5, 129.2, 129.6, $129.8,133.0,141.5,142.3,146.7,150.8$. FTIR $\left(\nu / \mathrm{cm}^{-1}\right): 3448$, 3032, 1589, 1489, 1327, 1280, 1080, 1033, 748, 694. (ESI-MS) $m / z$ : $[\mathrm{M}+\mathrm{H}]^{+}$calcd for $\mathrm{C}_{26} \mathrm{H}_{21} \mathrm{NOS} 396.1417$, found 396.1445.

(E)-1-(2-(Phenylsulfinyl)vinyl)pyrene (P4). Yellow solid. Yield: $0.540 \mathrm{~g}$ (68\%). Mp: $183{ }^{\circ} \mathrm{C} .{ }^{1} \mathrm{H}$ NMR (400 $\mathrm{MHz}, \mathrm{CDCl}_{3}, \mathrm{TMS}$ ) $\delta(\mathrm{ppm}): 8.42(\mathrm{~d}, J=15.1 \mathrm{~Hz}, 1 \mathrm{H}), 8.39(\mathrm{~d}, 1 \mathrm{H}), 8.16-7.93(\mathrm{~m}$, $8 \mathrm{H}), 7.77$ (d, 2H), 7.55-7.47 (m, 3H), 7.04 (d, $J=15.2 \mathrm{~Hz}, 1 \mathrm{H})$. ${ }^{13} \mathrm{C}$ NMR (100 MHz, $\left.\mathrm{CDCl}_{3}, \mathrm{TMS}\right) \delta$ (ppm): 122.4, 124.3, 124.6, $124.9,125.7,125.9$, 126.3, 127.2, 127.5, 128.4, 128.6, 129.2, 129.6, 130.7, 131.2, 131.3, 132.3, 133.4, 135.1, 144.1. FTIR $(\nu /$ $\mathrm{cm}^{-1}$ ): 3441, 3047, 1597, 1087, 1049, 941, 848, 709. Anal. calcd for $\mathrm{C}_{24} \mathrm{H}_{16} \mathrm{OS}$ : C, 81.79; H, 4.58. Found: C, 80.99; H, 5.08.

General procedure for the preparation of vinyl sulfones. To a dry $50 \mathrm{~mL}$ two-necked flask were added the vinyl sulfide $\mathbf{P 1}$ or P2 $(0.5 \mathrm{mmol})$ and $\mathrm{CH}_{2} \mathrm{Cl}_{2}(15 \mathrm{~mL})$. The system was cooled with ice-water bath and $m$ CPBA $(50 \%, 0.516 \mathrm{~g}, 1.5 \mathrm{mmol})$ was added and the reaction was stirred for approximately $24 \mathrm{~h}$ at room temperature. The reaction mixture was diluted with $\mathrm{CH}_{2} \mathrm{Cl}_{2}(10$ $\mathrm{mL})$ and washed with $30 \% \mathrm{Na}_{2} \mathrm{~S}_{2} \mathrm{O}_{3}$ solution $(2 \times 15 \mathrm{~mL})$ and $5 \% \mathrm{NaHCO}_{3}$ solution $(3 \times 15 \mathrm{~mL})$. The organic layer was dried over $\mathrm{MgSO}_{4}$ and concentrated under reduced pressure. The residue was purified by column chromatography, eluting with ethyl acetate/hexanes $(2: 8, \mathrm{v} / \mathrm{v})$.

(E)- $\boldsymbol{N}, \boldsymbol{N}$-Diphenyl-4-(2-(phenylsulfonyl)vinyl)aniline (P5). Yellow solid. Yield: $0.160 \mathrm{~g}$ (78\%). Mp: $161{ }^{\circ} \mathrm{C} .{ }^{1} \mathrm{H}$ NMR (400 $\mathrm{MHz}, \mathrm{CDCl}_{3}$, TMS) $\delta(\mathrm{ppm}): 7.93-7.90(\mathrm{~m}, 2 \mathrm{H}), 7.61-7.49(\mathrm{~m}$, $4 \mathrm{H}), 7.31-7.24(\mathrm{~m}, 6 \mathrm{H}), 7.10-7.07(\mathrm{~m}, 6 \mathrm{H}), 6.96(\mathrm{~d}, J=8.7 \mathrm{~Hz}$, $2 \mathrm{H}), 6.66(\mathrm{~d}, J=15.3 \mathrm{~Hz}, 1 \mathrm{H}) .{ }^{13} \mathrm{C} \mathrm{NMR}\left(100 \mathrm{MHz}, \mathrm{CDCl}_{3}, \mathrm{TMS}\right)$ $\delta$ (ppm): 121.2, 124.0, 124.4, 125.0, 125.6, 127.5, 129.2, 129.6, 129.8, 133.0, 141.5, 142.3, 146.7, 150.8. FTIR $\left(\nu / \mathrm{cm}^{-1}\right): 3448$, 3047, 1581, 1489, 1334, 1303, 1141, 1080, 702, 617, 501. (ESIMS) $m / z:[\mathrm{M}+\mathrm{H}]^{+}$calcd for $\mathrm{C}_{26} \mathrm{H}_{21} \mathrm{NO}_{2} \mathrm{~S}$ 412.1366, found 412.1385.

(E)-1-(2-(Phenylsulfonyl)vinyl)pyrene (P6). Yellow solid. Yield: $0.138 \mathrm{~g}$ (75\%). Mp: $190{ }^{\circ} \mathrm{C}$. ${ }^{1} \mathrm{H}$ NMR $\left(400 \mathrm{MHz}, \mathrm{CDCl}_{3}\right.$, TMS) $\delta$ (ppm): $8.75(\mathrm{~d}, J=15.1 \mathrm{~Hz}, 1 \mathrm{H}), 8.36(\mathrm{~d}, 1 \mathrm{H}), 8.20-$ $7.96(\mathrm{~m}, 10 \mathrm{H}), 7.64-7.52(\mathrm{~m}, 3 \mathrm{H}), 7.08$ (d, $J=15.1 \mathrm{~Hz}, 1 \mathrm{H})$. ${ }^{13} \mathrm{C}$ NMR (100 MHz, $\mathrm{CDCl}_{3}$, TMS) $\delta$ (ppm): 121.9, 124.4, 124.8, 124.9, 125.7, 126.2, 126.3, 126.4, 127.2, 127.8, 128.7, 129.1, 129.4, 130.1, 130.5, 131.2, 133.3, 133.4, 139.2, 141.0. FTIR $\left(\nu / \mathrm{cm}^{-1}\right): 3417,2916,1597,1319,1149,1080,840,578$. (ESI-MS) $\mathrm{m} / \mathrm{z}:[\mathrm{M}+\mathrm{H}]^{+}$calcd for $\mathrm{C}_{24} \mathrm{H}_{16} \mathrm{O}_{2} \mathrm{~S} 369.0944$, found 369.0960 . 


\section{Results and discussion}

Synthesis

The precursors, the phosphonates 1, 4 and 4-diphenylamino benzaldehyde (2) were prepared following reported procedures. The syntheses of the sulfur-based chromophores P1-P6, via the Horner-Wadsworth-Emmons reaction, are presented in Scheme 1.

The synthesis of the vinyl sulfides and sulfoxides was carried out by treatment of the appropriate aldehyde with the phosphonates 1 or 4 using $\mathrm{NaH}$ as base, in THF at $60^{\circ} \mathrm{C}$ for $24 \mathrm{~h}$. The sulfides P1 and P2 were obtained in excellent yields, 93\% and $89 \%$, respectively, with a clear preference for the $E$ isomers. The vinyl sulfoxides P3 and $\mathbf{P 4}$ were obtained in $71 \%$ and $68 \%$ yield, respectively. As expected, the stereoselectivity of the HWE reaction was very high, yielding $\mathbf{P} 3$ with clear preference for the $E$ isomer and $\mathbf{P 4}$ solely as the $E$ isomer. On the other hand, the vinyl sulfones $\mathbf{P 5}$ and $\mathbf{P 6}$ were successfully synthesized in good yields (78\% and $75 \%$, respectively) by oxidation of the vinyl sulfides $\mathbf{P 1}$ and $\mathbf{P 2}$ with $m$ CPBA. As observed in a previous work,,$^{31,40}$ the oxidation reaction caused the isomerization of the $Z$ isomers, yielding the sulfones as single $E$ isomers. The dyes P1-P6 were fully characterized by ${ }^{1} \mathrm{H}$ and ${ }^{13} \mathrm{C}$ NMR, FTIR, highresolution mass spectrometry (HRMS) or elemental analysis. The stereochemistry of the products was established on the basis of the coupling constants of the vinylic protons in their ${ }^{1} \mathrm{H}$ NMR spectra ( $J_{\text {trans }} \sim 15 \mathrm{~Hz}$ and $\left.J_{\text {cis }} \sim 10 \mathrm{~Hz}\right)$.

\section{Photophysical characterization}

The absorption spectra of the sulfur based compounds P1-P6 in different organic solvents are shown in Fig. 1 and 2. The relevant data from UV-Vis absorption spectroscopy are presented in Table 1. The UV-Vis absorption curves allowed to relate the

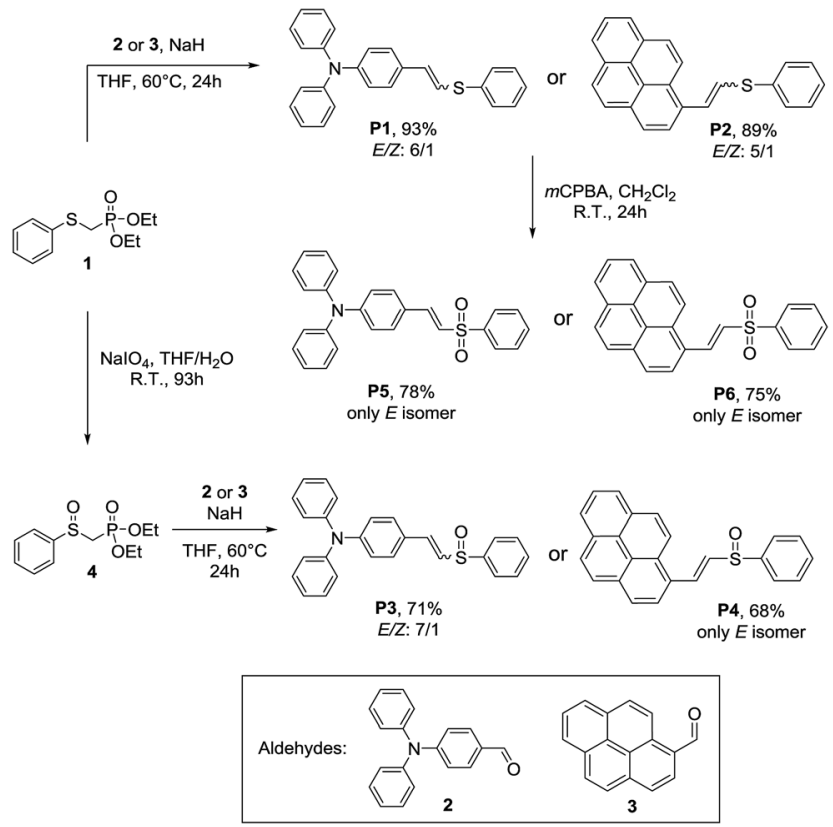

Scheme 1 Synthesis of the sulfur-based dyes P1-P6.
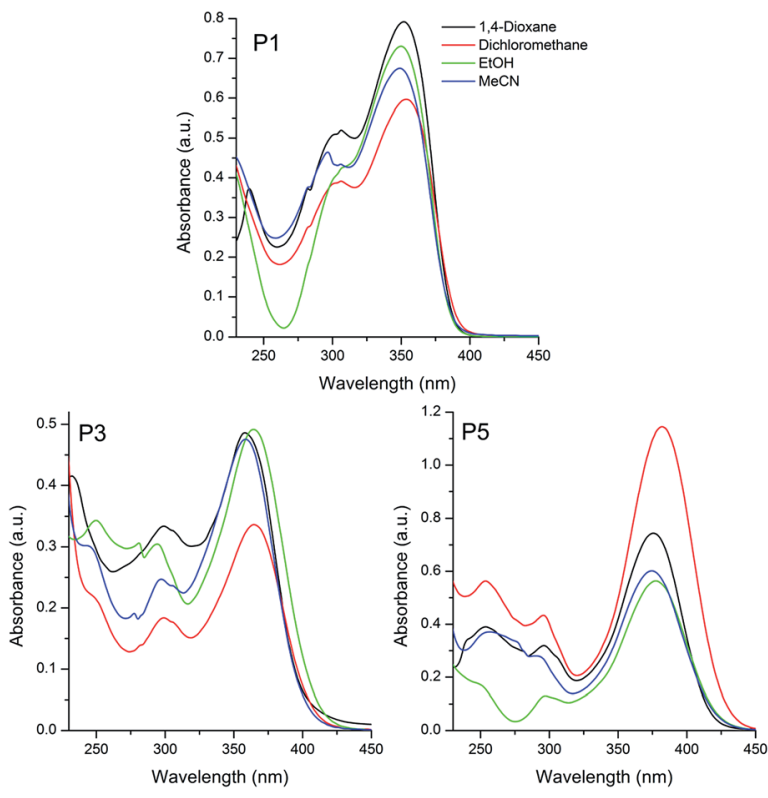

Fig. 1 UV-Vis absorption spectra of the sulfide P1, sulfoxide P3 and sulfone P5 based triphenylamino compounds in different organic solvents $\left[10^{-5} \mathrm{M}\right]$.
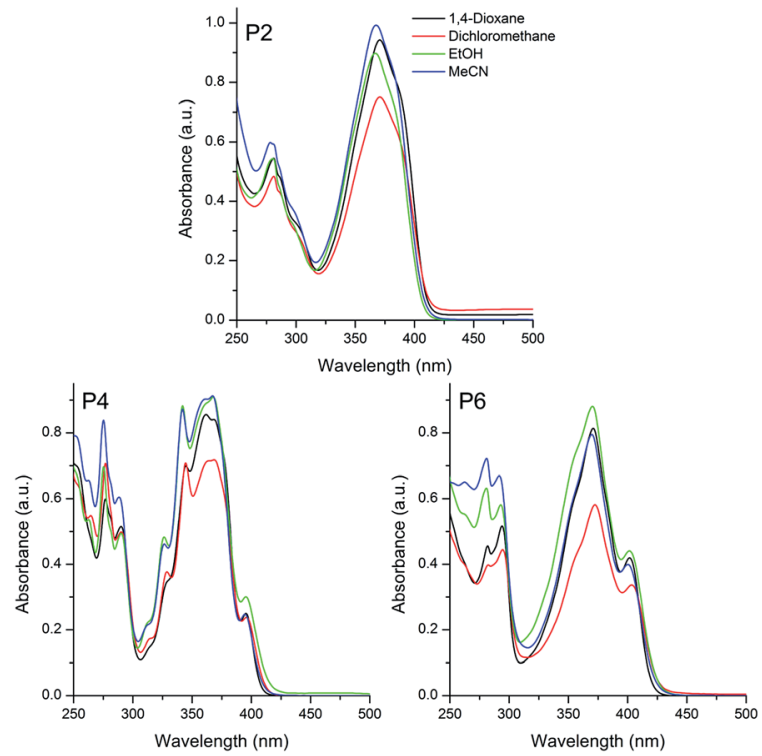

Fig. 2 UV-Vis absorption spectra of the sulphide (P2), sulfoxide (P4) and sulfone (P6) based pyrene compounds in different organic solvents $\left[10^{-5} \mathrm{M}\right]$.

experimental extinction coefficients $\varepsilon$ with the calculated radiative rate constants $k_{\mathrm{e}}^{0}$ and the oscillator strengths $\left(f_{\mathrm{e}}\right)$, using the Strickler-Berg relation presented in eqn (1), ${ }^{55}$

$$
f_{\mathrm{e}} \approx 4.3 \times 10^{-9} \int \varepsilon \mathrm{d} \bar{\nu}
$$

where the integral is the area under the absorption curve from the plot of the molar absorptivity coefficient $\varepsilon\left(\mathrm{M}^{-1} \mathrm{~cm}^{-1}\right) v s$. the wavenumber $\bar{\nu}\left(\mathrm{cm}^{-1}\right)$ corresponding to a single electron 
Table 1 Relevant photophysical data of the UV-Vis spectra, where the concentrations are presented in $10^{-5} \mathrm{M}, \lambda_{\text {abs }}$ is the absorption maxima $(\mathrm{nm}), \varepsilon$ is the molar absorptivity $\left(10^{4} \mathrm{M}^{-1} \mathrm{~cm}^{-1}\right), f_{\mathrm{e}}$ is the calculated oscillator strength, $k_{\mathrm{e}}^{0}$ is the calculated radiative rate constant $\left(10^{8} \mathrm{~s}^{-1}\right)$ and $\tau^{0}$ is the calculated pure radiative lifetime (in $\mathrm{ns}$ )

\begin{tabular}{llllllll}
\hline Dye & Solvent $^{a}$ & Conc. & $\lambda_{\text {abs }}$ & $\varepsilon$ & $f_{\mathrm{e}}$ & $k_{\mathrm{e}}^{0}$ & $\tau^{0}$ \\
\hline P1 & DIO & 2.21 & 352 & 3.59 & 0.96 & 7.71 & 1.30 \\
& DCM & 2.89 & 354 & 2.07 & 0.47 & 3.75 & 2.67 \\
& EtOH & 2.21 & 350 & 3.31 & 0.83 & 6.78 & 1.48 \\
& MeCN & 2.21 & 348 & 3.06 & 0.85 & 7.02 & 1.43 \\
P3 & DIO & 2.28 & 359 & 2.96 & 0.48 & 3.72 & 2.69 \\
& DCM & 1.79 & 364 & 1.88 & 0.39 & 2.91 & 3.43 \\
& EtOH & 1.79 & 365 & 2.75 & 0.61 & 4.57 & 2.19 \\
& MeCN & 1.79 & 359 & 2.66 & 0.51 & 3.98 & 2.51 \\
P5 & DIO & 2.19 & 376 & 3.39 & 0.62 & 4.42 & 2.26 \\
& DCM & 1.41 & 382 & 3.30 & 0.93 & 6.35 & 1.58 \\
& EtOH & 1.72 & 378 & 3.28 & 0.66 & 4.65 & 2.15 \\
& MeCN & 1.72 & 375 & 3.49 & 0.61 & 4.31 & 2.32 \\
P2 & DIO & 2.11 & 371 & 4.38 & 0.81 & 5.87 & 1.70 \\
& DCM & 2.49 & 370 & 2.87 & 0.57 & 4.18 & 2.39 \\
& EtOH & 1.63 & 367 & 5.52 & 0.97 & 7.19 & 1.39 \\
& MeCN & 2.03 & 368 & 4.91 & 0.79 & 5.84 & 1.71 \\
P4 & DIO & 2.19 & 362 & 3.91 & 0.69 & 5.26 & 1.90 \\
& DCM & 2.56 & 369 & 2.79 & 0.52 & 3.83 & 2.61 \\
& EtOH & 2.21 & 369 & 4.12 & 0.77 & 5.66 & 1.77 \\
& MeCN & 2.21 & 360 & 4.08 & 0.81 & 6.24 & 1.60 \\
P6 & DIO & 2.28 & 371 & 3.58 & 0.62 & 4.52 & 2.21 \\
& DCM & 2.10 & 372 & 2.57 & 0.52 & 3.77 & 2.65 \\
& EtOH & 2.28 & 370 & 3.88 & 0.64 & 4.69 & 2.13 \\
& MeCN & 2.28 & 370 & 3.51 & 0.76 & 5.55 & 1.80
\end{tabular}

${ }^{a}$ DIO $=1$,4-dioxane, DCM $=$ dichloromethane, $\mathrm{EtOH}=$ ethanol and $\mathrm{MeCN}=$ acetonitrile.

oscillator. The rate constant $\left(k_{\mathrm{e}}^{0}\right)$ for emission can be related to the extinction coefficient for absorption using the eqn (2), where the pure radiative lifetime, $\tau^{0}$ is defined as $1 / k_{\mathrm{e}}^{0.56}$

$$
k_{\mathrm{e}}^{0} \approx 2.88 \times 10^{-9} \bar{\nu}_{0}^{2} \int \varepsilon \mathrm{d} \bar{\nu} .
$$

The sulphur-based compounds containing the triphenylamino moiety presented absorption maxima located in the UV-A region (350, 362 and $378 \mathrm{~nm}$ for $\mathbf{P 1}, \mathbf{P} 3$ and $\mathbf{P 5}$, respectively) (Fig. 1). The molar absorptivity values $\left(\varepsilon, \sim 10^{4} \mathrm{M}^{-1} \mathrm{~cm}^{-1}\right)$ and the calculated radiative rate constants $\left(k_{\mathrm{e}}^{0}, \sim 10^{8} \mathrm{~s}^{-1}\right)$ indicated spin and symmetry allowed electronic transitions, related to ${ }^{1} \pi$ $\pi^{*}$ transitions. Although no relation was detected between the location of the absorption maxima and the solvent polarity, it was observed for all compounds a small solvatochromic effect $\left(\Delta \lambda_{\text {abs }} \sim 450 \mathrm{~cm}^{-1}\right)$, indicating an almost absent charge transfer character in the ground-state.

A similar photophysical behaviour could be observed for the pyrene derivatives P2, P4 and P6, where ${ }^{1} \pi-\pi^{*}$ electronic transitions were ascribed to the absorption maxima located at 369 , 365 and $371 \mathrm{~nm}$, respectively (Fig. 2). In addition, despite the presence of electron withdrawing and electron donating groups (EWG and EDG, respectively) in the $\pi$-conjugated system, the small value for the $\Delta \lambda_{\text {abs }}\left(\sim 370 \mathrm{~cm}^{-1}\right)$, also indicated the absence of charge transfer state in these compounds in the ground-state.
It is worth mentioning that the studied sulfur derivatives containing the triphenylamino moiety P1, P3 and P5 presented a redshift on the location of the absorption maxima with increase of the electron withdrawing effect, from sulfide to sulfone (24-28 $\mathrm{nm})$. Since this behavior is not observed in P2, $\mathbf{P 4}$ and P6, the redshift cannot be related only to changes in the withdrawing effect of the chromophore (sulfide-sulfoxide-sulfone). Thus, it is believed that the donating effect is also playing an important role on the observed photophysical behaviour, because the pyrene presents lower donor ability than the triphenylamino group. An almost constant radiative lifetime $\left(\tau^{0} \sim 2 \mathrm{~ns}\right)$ was calculated for the compounds in all studied solvents, indicating that after radiation absorption, the dyes populate the same excited state.

The fluorescence emission spectra of compounds P1-P6 are shown in Fig. 3 and 4. The relevant data from the steady-state fluorescence spectroscopy are presented in Table 2. The emission curves were obtained by exciting the compounds at the absorption maxima wavelength. The sulfur based compounds containing the triphenylamino moiety presented a main emission band located in the violet-green region, which can be related to a vertical transition from the lowest excited state with the largest oscillator strength, as observed in Table 1 for the almost unitary values of $f_{\mathrm{e}}$. For all compounds a significant redshift $\left(\Delta \lambda_{\mathrm{em}}\right)$ on the emission maxima is observed with increasing the solvent polarity. Values from 36 to $85 \mathrm{~nm}$ (1915 to $3531 \mathrm{~cm}^{-1}$ ) were calculated for sulfide to sulfone compounds.

The positive solvatochromism can be related to a better electron delocalization in the excited state afforded by an intramolecular charge transfer state in these compounds.

The increase of the calculated Stokes' shift with increase of the dielectric constant of the solvent (1,4-dioxane to acetonitrile) is consistent with the stabilization of the charge transfer state by the polar solvents (Table 2).

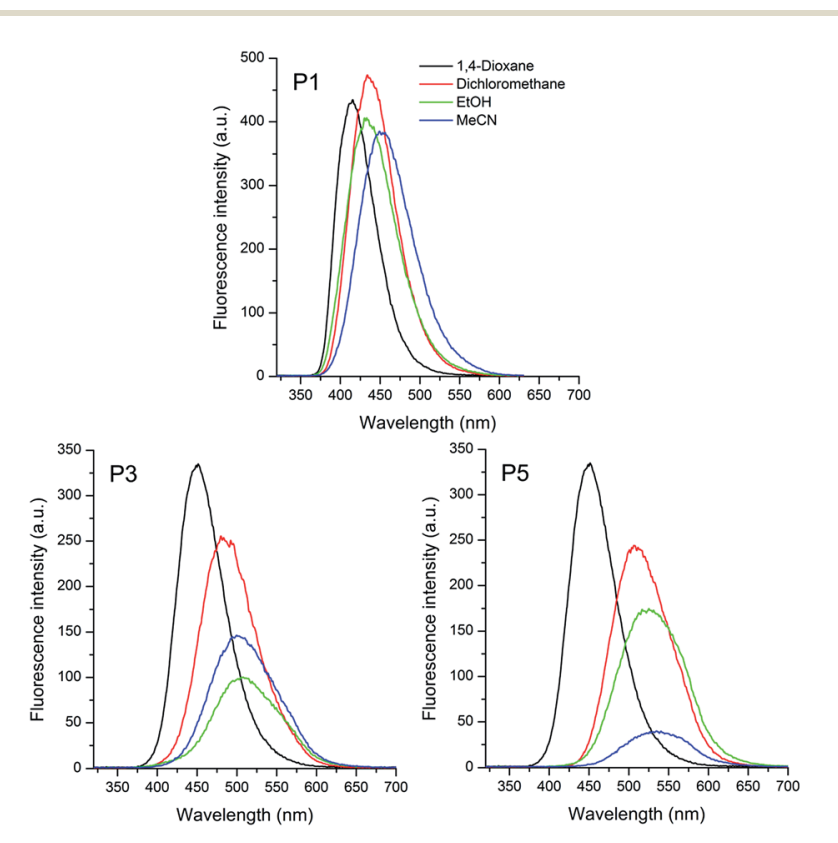

Fig. 3 Fluorescence spectra of the sulphide (P1), sulfoxide (P3) and sulfone (P5) based triphenylamino compounds in different organic solvents $\left[10^{-5} \mathrm{M}\right]$. 

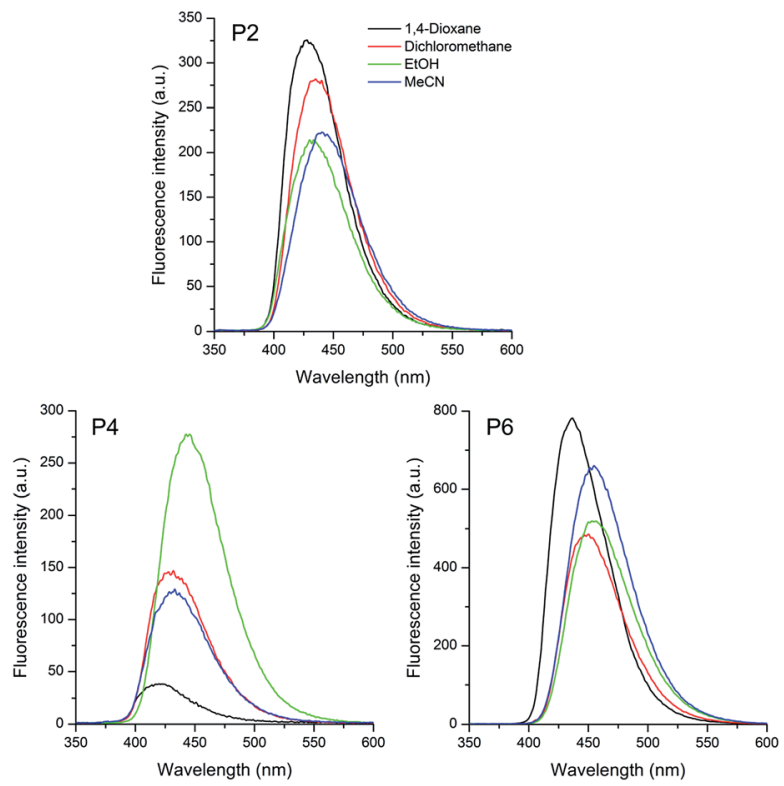

Fig. 4 Fluorescence emission spectra of the sulfide P2, sulfoxide P4 and sulfone $\mathrm{P} 6$ based pyrene compounds in different organic solvents $\left[10^{-5} \mathrm{M}\right]$

Table 2 Relevant photophysical data of the fluorescence spectra, where $\lambda_{\mathrm{em}}$ is the emission maxima $(\mathrm{nm}), \Delta \lambda_{\mathrm{ST}}$ is the Stokes' shift ( $\mathrm{nm}$ $\left.\mathrm{cm}^{-1}\right), \Delta \lambda_{\text {em }}$ is the solvatochromism in the excited state $\left(\mathrm{nm} \mathrm{cm}^{-1}\right)$ and $\Phi_{\mathrm{FL}}$ is the fluorescence quantum yield (\%)

\begin{tabular}{lllllll}
\hline Dye & Solvent $^{a}$ & Solvent & $\lambda_{\text {em }}$ & $\Delta \lambda_{\text {em }}$ & $\Delta \lambda_{\mathrm{ST}}$ & $\Phi_{\mathrm{FL}}$ \\
\hline P1 & DIO & Hexane & 416 & $36 / 1915$ & 4371 & 0.34 \\
& DCM & Toluene & 437 & & 5365 & 0.22 \\
& EtOH & 1,4-Dioxane & 434 & & 5694 & 0.32 \\
& MeCN & Dichloromethane & 452 & & 6612 & 0.46 \\
P3 & DIO & Hexane & 450 & $51 / 2262$ & 5633 & 0.27 \\
& DCM & Toluene & 483 & & 6683 & 0.27 \\
& EtOH & 1,4-Dioxane & 506 & & 7634 & 0.45 \\
& MeCN & Dichloromethane & 501 & & 7895 & 0.35 \\
P5 & DIO & Hexane & 450 & $85 / 3531$ & 6533 & 0.29 \\
& DCM & Toluene & 508 & & 6493 & 0.33 \\
& EtOH & 1,4-Dioxane & 524 & & 7371 & 0.45 \\
& MeCN & Dichloromethane & 535 & & 7975 & 0.20 \\
P2 & DIO & Hexane & 428 & $13 / 689$ & 3590 & 0.26 \\
& DCM & Toluene & 435 & & 4039 & 0.23 \\
& EtOH & 1,4-Dioxane & 433 & & 4153 & 0.25 \\
& MeCN & Dichloromethane & 441 & & 4498 & 0.25 \\
P4 & DIO & Hexane & 417 & $16 / 886$ & 3643 & 0.44 \\
& DCM & Toluene & 432 & & 3952 & 0.48 \\
& EtOH & 1,4-Dioxane & 444 & & 4578 & 0.32 \\
& MeCN & Dichloromethane & 433 & & 4683 & 0.16 \\
P6 & DIO & Hexane & 430 & $25 / 1278$ & 3698 & 0.47 \\
& DCM & Toluene & 449 & & 4610 & 0.25 \\
& EtOH & 1,4-Dioxane & 455 & & 5049 & 0.36 \\
& MeCN & Dichloromethane & 455 & & 5049 & 0.45
\end{tabular}

${ }^{a}$ DIO $=1,4$-dioxane, $\mathrm{DCM}=$ dichloromethane, $\mathrm{EtOH}=$ ethanol and $\mathrm{MeCN}=$ acetonitrile.

Moreover, this effect is greater in the sulfone derivative P5 due to higher electronic withdrawing character of this group relative to sulfoxide $\mathbf{P} \mathbf{3}$ and sulfide $\mathbf{P 1}$.
This behaviour indicates that the excited state of these compounds is more polar than the ground state one, i.e. $\mu_{\mathrm{e}}>\mu_{\mathrm{g}}$. In this scenario, the relaxed excited state seems to be more stabilized relative to the ground state by increasing the polarity of the solvent.

As already observed for compounds P1, P3 and P5, the pyrene based sulfur compounds also present a single emission band located in the visible region of the spectra (violet to blue). Values from the calculated oscillator strength also allowed to relate the observed deactivation pathway with the lowest excited state. Although much less intense than the triphenylamino analogues, a redshift on the emission maxima $\left(\Delta \lambda_{\mathrm{em}}\right)$ was also observed with changes in the solvent polarity. Compounds P2, $\mathbf{P 4}$ and P6 presented values from 13 to $25 \mathrm{~nm}$ (689 to 1278 $\mathrm{cm}^{-1}$ ), increasing from sulfide to sulfone derivatives, which can also be related to a ICT state. This difference is probably due to the less donating character of the pyrene group with regard to the triphenylamino moiety. Once again the sulfone derivative P6 presented the highest redshift due to higher electronic withdrawing character of this group compared to sulfoxide $\mathbf{P 4}$ and sulfide P2. In these compounds, the Stokes' shift values also relates to an ICT state in the excited state. It is worth mentioning that in ethanol some compounds presented an unexpected behaviour due to a specific solvent-fluorophore interaction, such as hydrogen bonding. ${ }^{57}$ The calculated fluorescence quantum yields $\left(\Phi_{\mathrm{FL}}\right)$ were in agreement with the values reported in the literature for push-pull vinylic compounds $^{58}$ or sulfur compounds containing EDG or EWG moieties. ${ }^{20,37,59,60}$ The almost similar $\Phi_{\mathrm{FL}}$ calculated for all compounds indicate that different electron donating groups, as well as the oxidation state of the sulfur atom do not affect significantly the excited singlet state deactivation. Similar sulfoxide derivatives bearing a pyrene moiety were reported in fluorescence chemosensor applications. ${ }^{\mathbf{6 1}}$ The very low fluorescence quantum yields were related to excited-state pyramidal inversion of the sulfoxide-appended fluorophores, ${ }^{62}$ which were suppressed after metal coordination. Besides the extension of the $\pi$-conjugation provided by the vinyl moiety, this group also seems to play an interesting role in the photophysics of the studied compounds. The observation of higher fluorescence quantum yields suggests that minimization of the pyramidal inversion of the sulfoxide is operative, as an excited state deactivation channel. On the other side, the shape of the absorption and emission spectra of the pyrene derivatives are different from those observed in similar compounds. ${ }^{37,61}$

To better understand the extend of the intramolecular charge transfer character in these compounds, the difference in the dipole moment between the excited and ground states $\left(\Delta \mu_{\text {eg }}\right)$ were obtained for dyes P1, P3 and P5 using the LippertMataga eqn (3): ${ }^{63}$

$$
\Delta \bar{\nu}_{\mathrm{ST}}=\frac{2\left(\Delta \mu_{\mathrm{eg}}\right)^{2}}{h c a^{3}} \Delta f+\Delta \bar{\nu}_{0}
$$

This equation compares the solvatochromic shifts from the absorption and emission maxima, as well as the Stokes' shift versus the orientation polarization function $(\Delta f),{ }^{56,57}$ were 
a linear correlation indicates intramolecular charge transfer character. ${ }^{64}$ In this equation, $h$ is the Planck's constant, $c$ is the speed of light, $a$ is the Onsager cavity radius, which was obtained in gas phase using CAM-B3LYP/jun-cc-pVTZ level of theory. For these calculations were used values 0.5 angstrom smaller than those calculated (5.44, 5.36 and 5.12 angstrom for P1, P3 and P5, respectively).

Fig. 5 presents the Lippert plot of the absorption, fluorescence emission maxima and Stokes' shift $\left(\Delta \bar{\nu}_{\mathrm{ST}}=\bar{\nu}_{\mathrm{abs}}-\bar{\nu}_{\mathrm{em}}\right)$ versus the orientation polarisability $(\Delta f)$ for P1, P3 and P5. Any significant solvatochromic effect was observed taking the absorption maxima into account (Fig. 5a), which can be related to absence of charge transfer in the ground state. On the other hand, the negative slope on the emission maxima, as well as the increasing slope on the Stokes' shift (Fig. 5b and c, respectively) indicate intramolecular charge transfer (ICT) mechanism in the excited state. From the slope of the Stokes' shift versus the orientation polarisability plot, the change in the dipole moment $\left(\Delta \mu_{\mathrm{eg}}\right)$ of the fluorophores upon excitation was estimated as 15.40 D for P1, 14.76 D for P3 and 14.43 D for P5. It is worth to mention that the ICT process, as well as the significative difference in the dipole moment between the excited and ground states were already predicted by theoretical calculations obtained in this work.

\section{Theoretical calculations}

The wavelengths of the absorption and emission maxima obtained with the CAM-B3LYP functional are shown in Table 3. A comparison between these results and those obtained with PBE1PBE is shown in the ESI (Table ESI1 $\dagger$ ). It is known from the literature that CAM-B3LYP generally provides a better description of the excited states with charge transfer and Rydberg

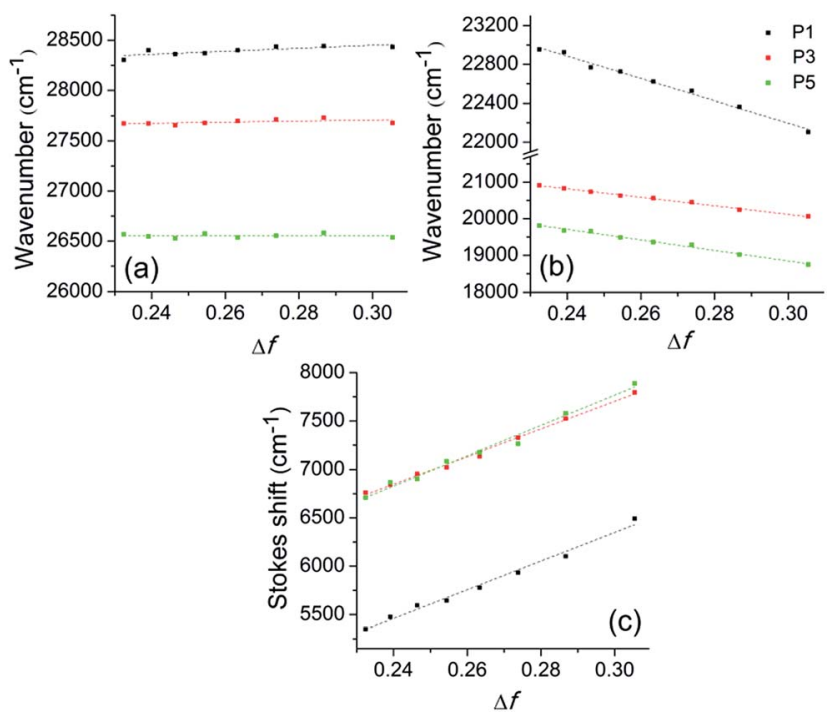

Fig. 5 Solvent effect on the (a) absorption maxima, (b) fluorescence emission and (c) Stokes' shift of the sulfide P1, sulfoxide P3 and sulfone P5. $\Delta f$ is given as $\Delta f=[(\varepsilon-1) /(2 \varepsilon+1)]-\left[\left(n^{2}-1\right) /\left(2 n^{2}+1\right)\right]$, where $\varepsilon$ is dielectric constant and $n$ is the refractive index for a mixture of solvents. ${ }^{56}$
Table 3 Calculated photophysical data of the P1-P6 dyes, where $\lambda_{\text {abs }}$ and $\lambda_{\mathrm{em}}$ are the absorption and emission maxima, respectively $(\mathrm{nm}), f_{\mathrm{e}}$ is the theoretical oscillator strength and $\mu$ is the dipole moment (D) for molecules in their respective $S_{0}$ (ground) and $S_{1}$ (excited) electronic states

\begin{tabular}{|c|c|c|c|c|c|c|c|}
\hline \multirow[b]{2}{*}{ Dye } & \multirow[b]{2}{*}{ Solvent $^{a}$} & \multicolumn{3}{|l|}{$\mathrm{S}_{0}$} & \multicolumn{3}{|l|}{$\mathrm{S}_{1}$} \\
\hline & & $\lambda_{\mathrm{abs}}$ & $f_{\mathrm{e}}$ & $\mu$ & $\lambda_{\mathrm{em}}$ & $f_{\mathrm{e}}$ & $\mu$ \\
\hline \multirow[t]{5}{*}{ P1 } & $\mathrm{DIO}^{b}$ & 368 & 0.853 & 1.85 & 451 & 0.785 & 10.98 \\
\hline & DIO & 329 & 0.938 & 1.83 & 412 & 0.999 & 4.19 \\
\hline & DCM & 330 & 0.945 & 2.09 & 427 & 1.140 & 4.98 \\
\hline & EtOH & 329 & 0.930 & 2.17 & 431 & 1.174 & 5.18 \\
\hline & MeCN & 329 & 0.926 & 2.18 & 432 & 1.180 & 5.22 \\
\hline \multirow[t]{5}{*}{ P3 } & $\mathrm{DIO}^{b}$ & 374 & 0.891 & 5.19 & 486 & 0.206 & 25.82 \\
\hline & DIO & 331 & 0.990 & 5.18 & 385 & 1.007 & 12.40 \\
\hline & DCM & 332 & 1.006 & 5.98 & 407 & 1.194 & 13.46 \\
\hline & EtOH & 331 & 0.996 & 6.23 & 412 & 1.235 & 13.79 \\
\hline & MeCN & 331 & 0.993 & 6.27 & 414 & 1.243 & 13.87 \\
\hline \multirow[t]{5}{*}{ P5 } & $\mathrm{DIO}^{b}$ & 395 & 0.923 & 7.98 & 531 & 0.120 & 29.72 \\
\hline & DIO & 343 & 1.073 & 7.83 & 399 & 0.965 & 18.28 \\
\hline & DCM & 346 & 1.101 & 8.86 & 419 & 1.181 & 19.03 \\
\hline & EtOH & 346 & 1.097 & 9.17 & 425 & 1.236 & 19.33 \\
\hline & MeCN & 346 & 1.094 & 9.23 & 427 & 1.246 & 19.39 \\
\hline \multirow[t]{5}{*}{ P2 } & $\mathrm{DIO}^{b}$ & 396 & 0.848 & 1.77 & 485 & 0.987 & 4.41 \\
\hline & DIO & 354 & 0.922 & 1.73 & 447 & 1.115 & 2.14 \\
\hline & DCM & 354 & 0.929 & 1.94 & 471 & 1.366 & 2.47 \\
\hline & EtOH & 353 & 0.904 & 2.00 & 479 & 1.437 & 2.56 \\
\hline & MeCN & 353 & 0.897 & 2.01 & 480 & 1.450 & 2.58 \\
\hline \multirow[t]{5}{*}{ P4 } & $\mathrm{DIO}^{b}$ & 384 & 0.915 & 4.24 & 444 & 1.068 & 4.76 \\
\hline & DIO & 350 & 0.984 & 4.36 & 420 & 1.155 & 4.84 \\
\hline & DCM & 350 & 0.986 & 5.15 & 445 & 1.392 & 5.66 \\
\hline & EtOH & 349 & 0.960 & 5.41 & 453 & 1.454 & 5.92 \\
\hline & MeCN & 349 & 0.953 & 5.45 & 454 & 1.465 & 5.96 \\
\hline \multirow[t]{5}{*}{ P6 } & $\mathrm{DIO}^{b}$ & 403 & 0.898 & 6.64 & 452 & 1.026 & 12.94 \\
\hline & DIO & 362 & 0.998 & 6.61 & 428 & 1.154 & 10.49 \\
\hline & DCM & 365 & 1.004 & 7.59 & 458 & 1.385 & 11.82 \\
\hline & EtOH & 364 & 0.979 & 7.88 & 468 & 1.445 & 12.21 \\
\hline & MeCN & 364 & 0.972 & 7.94 & 469 & 1.456 & 12.29 \\
\hline
\end{tabular}

${ }^{a}$ DIO $=1,4$-dioxane, $\mathrm{DCM}=$ dichloromethane, $\mathrm{EtOH}=$ ethanol and $\mathrm{MeCN}=$ acetonitrile. ${ }^{b}$ Calculated with PBE1PBE/jun-cc-pVTZ// PBE1PBE/cc-pVDZ. The remaining data were calculated with CAMB3LYP/jun-cc-pVTZ//CAM-B3LYP/cc-pVDZ.

states than hybrid functionals, like PBE1PBE.46,48,50 However, the latter is well known for furnishing good results in the absorption and emission calculated spectra, and exhibiting mean absolute errors about $0.30 \mathrm{eV}$ on determinations of wavelength maxima. ${ }^{\mathbf{4 8 5 0 , 6 5 - 6 7}}$ CAM-B3LYP is a range separated exchange and LYP correlation, which allows an improvement on the description of charge transfer states. ${ }^{50}$ This is an important fact to be taken into account when studying molecules which could have a strong ICT character, like those with a D- $\pi-\mathrm{A}$ structure. ICT plays a key role in solar energy conversion devices, as it impacts directly into the dye efficiency as sensitizer. ${ }^{68,69}$

In the present work, CAM-B3LYP provided a better description of the absorption and emission spectra, presenting a lower mean deviation on absorption and emission maxima compared to the experimental data (Table ESI1 $\dagger$ ). Thus, the geometries and electronic properties of the compounds will be discussed based only on CAM-B3LYP calculations. 
Calculated vertical absorption and emission wavelength maxima for the molecules P1-P6 can be seen in Table 3. Changes in the absorption and emission wavelengths were observed by changing the donor and acceptor groups attached to the central part of the molecule. In P1, P3, and P5 the presence of the donor group triphenylamino leads to absorption maxima located around 329, 331, and $345 \mathrm{~nm}$, respectively. By changing the donor group to pyrene (P2, P4, and P6), the mean values of absorption wavelength maxima are shifted to 353, 350 and $363 \mathrm{~nm}$, respectively. In general, the oxidation of vinyl sulfides, producing the respective vinyl sulfoxides and sulfones, causes deviations to red in the absorption wavelength maxima. This tendency is the same observed in the experimental results and can be related to the increase of the electron withdrawing effect from sulfide to sulfone and to the nature of the electron-donating group. Since the triphenylamino group has greater donor ability than pyrene, it is possible to see higher charge separation in P1, P3, but mainly in P5, as observed in the HOMO-LUMO plots (Fig. 7). In addition, the high oscillator strength in all cases indicates a high probability of transition associated to HOMOLUMO, that can be assigned to ${ }^{1} \pi-\pi *$ electronic transitions.

The increase in solvent polarity did not present a significant effect in the absorption maxima, indicating the lack of solvatochromic effects in the ground state. In contrast, the main emission bands showed a significant bathochromic effect when the dielectric constant of the solvent was increased. This effect was higher when the solvent was changed from 1,4-dioxane to dichloromethane and can be assigned to a greater stabilization of the molecules by the solvent in the excited state than in the ground state. Since the molecules are more polar in $\mathrm{S}_{1}$, an increase in the solvent polarity will stabilize the first excited state more than the ground state. ${ }^{70}$ It has also been noted that changes in dipole moment from $S_{0}$ to $S_{1}$ are more significant in sulfones than in sulfides and sulfoxides. This can be attributed to the higher electron-withdraw character of the former group. In addition, the higher electron-donating character of the triphenylamino group helps to increase the difference in dipole moment from $S_{0}$ to $S_{1}$, improving the charge separation and enabling the existence of an intramolecular charge transfer state in the molecule (that aspect will be subsequently discussed).

Fig. 6 shows the optimized geometries calculated for the ground and first excited states using CAM-B3LYP and 1,4dioxane as solvent. The main differences in bond lengths and angles for the structures are summarized in Tables ESI2 and ESI3. $\uparrow$ Since the $E$ isomer was the major product in all cases, only the geometries of these isomers were calculated. For P1, P3, and P5, in the ground state, it can be seen that both external phenyl rings are out-of-plane, presenting a dihedral angle $d_{1}$ of approximately $45^{\circ}$. The central phenyl ring is in the same plane of the double bond, showing a dihedral angle $d_{2}$ around $0^{\circ}$. In excited state, $d_{1}$ comes close to $35^{\circ}$, while $d_{2}$ undergoes a small variation, assuming a planar structure along the $\pi$-bridge part of the conjugated system, in agreement with previous reports in the literature. ${ }^{71}$ It is interesting to note that the phenyl ring attached to sulfur is not in the same plane of the $\pi$ bridge, being almost perpendicular to it $\left(d_{3}\right)$. Upon excitation, there is

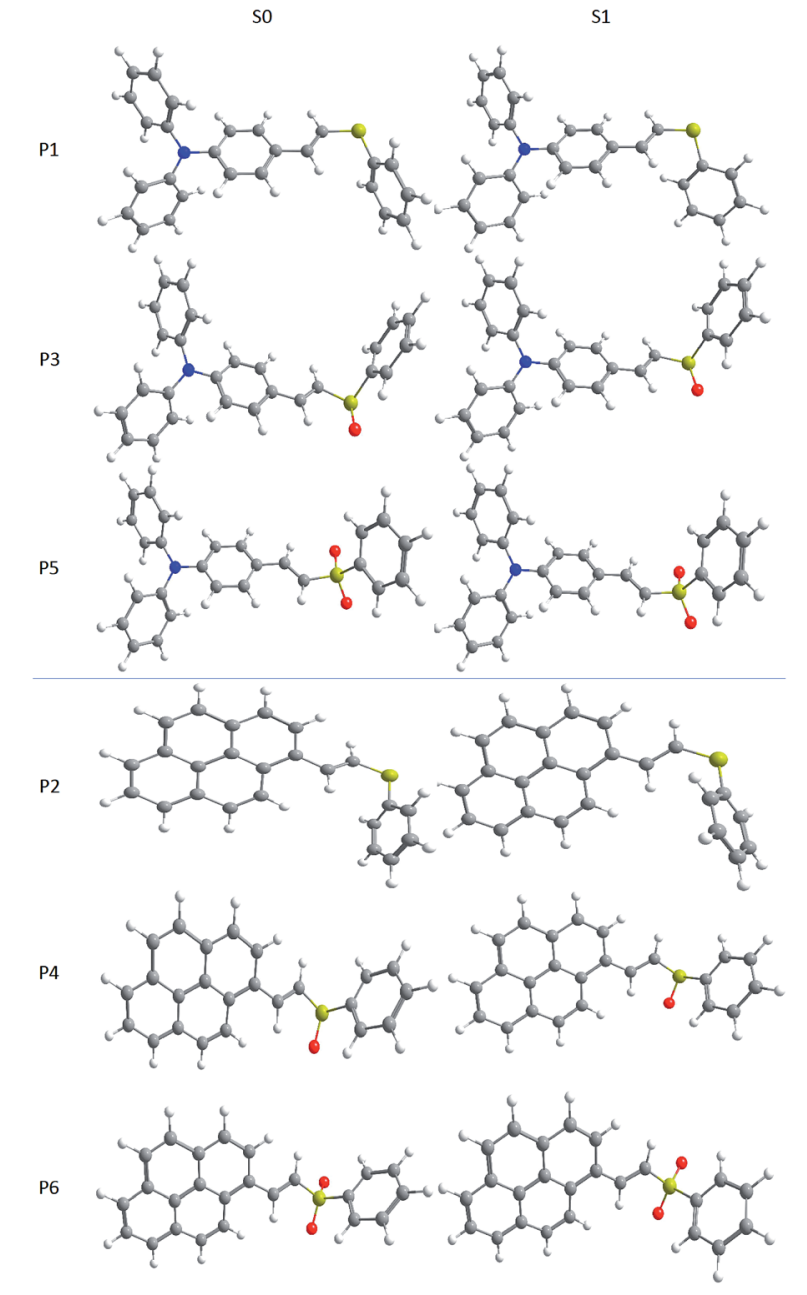

Fig. 6 Molecular geometries of the P1-P6 dyes in the ground (left) and first excited (right) states, calculated at the CAM-B3LYP level in 1,4-dioxane.

a rotation of this ring in $\mathbf{P 1}$, while no significant rotation is observed in $\mathbf{P 3}$ and P5. Compounds P2, P4, and P6 have a pyrene motif as donor. In these molecules, the dihedral angle between the pyrene moiety and the double bond is in the range of $16-30^{\circ}$ in the ground state, and becomes almost planar in the excited state. In the same way as in P1, P3 and P5, the phenyl ring bonded to the sulfur is not in the same plane of the remainder part of the molecule, being almost perpendicular to it, and rotating in $\mathbf{P 2}$ from $\mathrm{S}_{0}$ to $\mathrm{S}_{1}$. Comparing the geometries of the ground and excited states, the attachment of oxygen atoms to the sulfur does not lead to significant changes in the structures. This is reflected in a small geometrical reorganization after the electronic transition. By changing the solvent, a very small shift is observed in the geometries, as can be seen in Table ESI2. $\dagger$

The geometry of the molecules has an important role in systems that can present intramolecular charge transfer. For example, it is expected that the planarity of the donor moiety and the whole conjugated system (donor- $\pi$-bridge-acceptor) improves the mobility of electrons, resulting in a better charge transfer. ${ }^{68}$ The molecules under study have a D- $\pi-\mathrm{A}$ structure, which is desirable for a sensitizer, as it helps to separate 
spatially the HOMO and LUMO molecular orbitals. ${ }^{69}$ In fact, despite pyrene derivatives are more planar than the triphenylamino derivatives, this does not improve the charge separation in the molecules, as can be seen in Fig. 7. As the change in the dielectric constant of the solvent has no considerable effect in molecular orbitals, these plots are representative for all studied solvents (Fig. ESI1 and ESI2†).

It is possible to observe that in P1, the HOMO is localized at the donor group (triphenylamino or pyrene), but the LUMO is in the same group. This means that there is not an efficient charge separation, but the addition of oxygen atoms can help to improve this behaviour. Mainly in P5, a clear spatial separation of HOMO and LUMO can be observed, which means that P5 presents an ICT character. Furthermore, the large redshift in the maxima emission wavelength and the large dipole moment changes between the ground and first excited states are evidences of the ICT character in P5.

On the other hand, P2, P4 and P6 undergo a different pathway, since pyrene has a small electron-withdrawing character. The attachment of oxygen atoms to sulfur still increases the molecular orbital separation (even poorly from P2 to P4 and

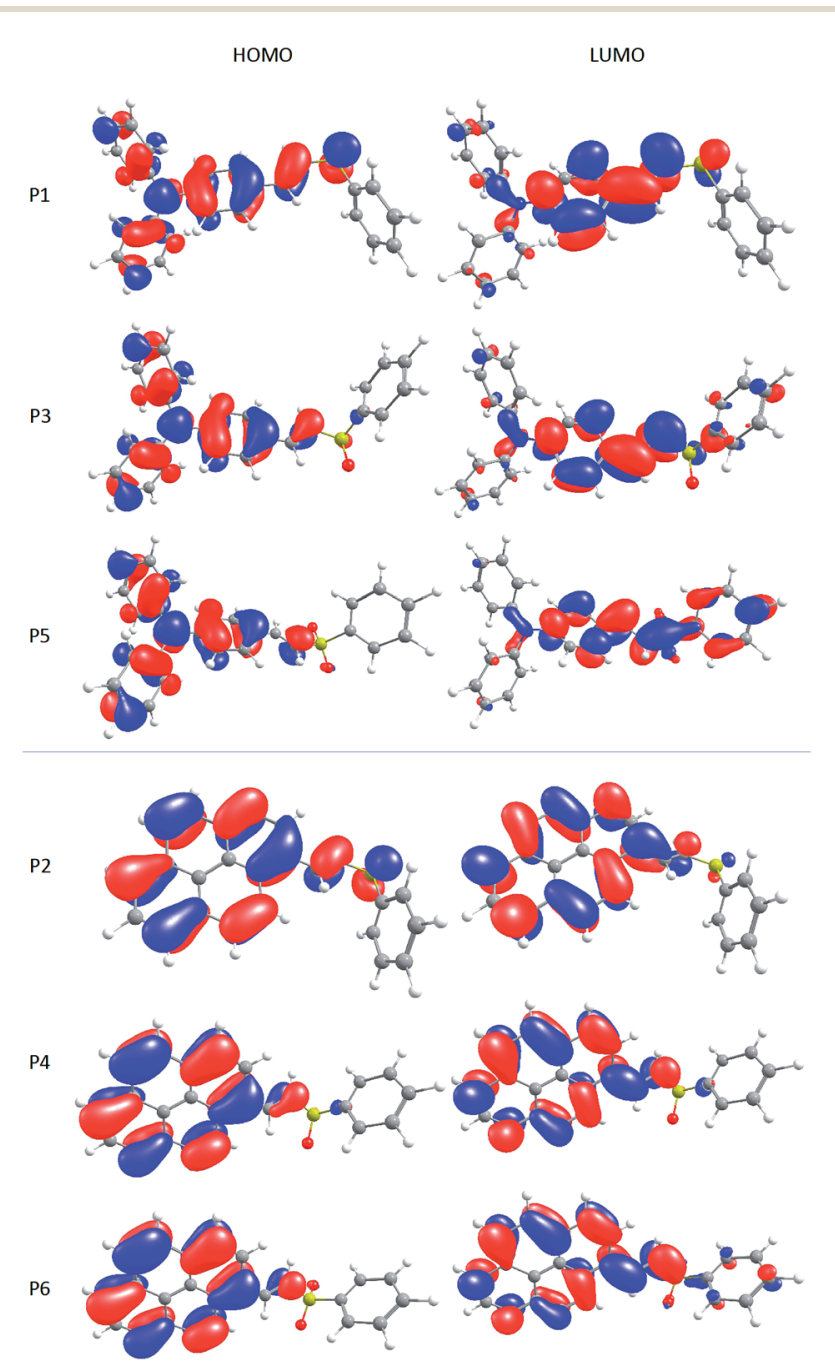

Fig. 7 HOMO and LUMO of the P1-P6 dyes, calculated at the CAMB3LYP level in 1,4-dioxane. a little bit better from P4 to P6). However, the HOMO and LUMO are virtually in the same portion of the molecule, indicating a local excitation, leading to a high electron-hole recombination rate. ${ }^{69,72}$

The charge transfer character could be evaluated using descriptors based in TD-DFT, like the $\Delta r$-index. This descriptor was proposed in 2013 by Guido et al. and is based on the distances between the centroids of the orbitals involved in the excitations and interpreted in terms of the hole-electron distance. ${ }^{72}$ This distance is related to the nature of the electronic transition since, often, local excitations are characterized by short distances, while larger distances are usually found for charge transfer excitations. Using this descriptor, available in Multiwfn, a multifunctional wavefunction analyzer, ${ }^{73}$ we have obtained values equal to 1.8, 3.2, $4.1 \AA$ for P1, P3 and P5, respectively and values equal to $0.9,0.9$ and $1.5 \AA$ for P2, P4 and P6, respectively. According to the authors, these values indicate that charge transfer excitations are expected only for P3 and P5, in agreement with our previous discussion based on HOMOLUMO separations and dipole momenta variations.

\section{Conclusions}

In summary, new vinyl sulfides and sulfoxides were successfully synthesized by reaction of appropriate aldehydes (triphenylamine and pyrene derivatives) and phosphonates, using $\mathrm{NaH}$ as base. These compounds were obtained in excellent yields with a clear preference for the $E$ isomers. It could also be observed that the stereoselectivity of the Horner-Wadsworth-Emmons reaction was significantly high. In addition, the related vinyl sulfones were also accessed in good yields by a simple oxidation step of the respective vinyl sulfides using $m$ CPBA. The oxidation reaction took place with isomerization of the $Z$ isomers, yielding the sulfones as single $E$ isomers. The introduction of sulfoxide and sulfones as electron-withdrawing groups resulted in a series of small dyes with the $\mathrm{D}-\pi-\mathrm{A}$ structure. All studied compounds presented absorption maxima located in the UV-A region with molar absorptivity coefficient $\varepsilon$ values $\left(\sim 10^{4} \mathrm{M}^{-1}\right.$ $\left.\mathrm{cm}^{-1}\right)$ and calculated radiative rate constants $k_{\mathrm{e}}^{0}\left(\sim 10^{8} \mathrm{~s}^{-1}\right)$ related to spin and symmetry allowed ${ }^{1} \pi-\pi^{*}$ electronic transitions. For both sets of compounds, despite the presence of electron withdrawing and electron donating groups in the vinylic conjugated system, a small solvatochromic effect was observed, indicating an almost absent charge transfer character in the ground-state. The sulfur based compounds containing the triphenylamino moiety present a main emission band located in the violet-green region. These compounds show a significant redshift on the emission maxima with increasing solvent polarity (1915 to $3531 \mathrm{~cm}^{-1}$, from sulfide to sulfone, respectively). The positive solvatochromism can be related to a better electron delocalization in the excited state resulting from an intramolecular charge transfer state in these compounds. Moreover, this effect is greater in the sulfone derivative due to the higher electronic withdrawing character of this group relative to sulfoxides and sulfides. The pyrene based sulfur compounds also present an emission band in the violetblue region. A less intense redshift in the emission maxima with 
increasing solvent polarity was observed in the pyrene derivatives due to the less donating character of the pyrene group relative to the triphenylamino moiety. DFT and TD-DFT calculations were performed at the PBE1PBE and CAM-B3LYP levels. The CAM-B3LYP functional presented a better agreement with the experimental photophysical data. In the ground state no solvatochromic effect was observed. On the other hand, a bathochromic effect was detected in the emission maxima when the solvent dielectric constant was increased. This behavior indicates a higher stabilization of $S_{1}$ compared to $S_{0}$. All the vertical electronic transitions can be assigned to a ${ }^{1} \pi-\pi^{*}$ character. Starting from sulfides to sulfones, the addition of oxygen atoms improves the charge separation, enabling an ICT state mostly in P3 and P5. This charge separation is more evident among the triphenylamino derivatives than in the pyrene derivatives, since the first one has a better electron-donating character.

\section{Acknowledgements}

The authors thank CNPq, CAPES and Instituto Nacional de Inovação em Diagnósticos para a Saúde Pública (INDI-Saúde) for financial support and scholarships. Theoretical calculations were carried out with the support of the Centro Nacional de Supercomputação (CESUP), from the Universidade Federal do Rio Grande do Sul.

\section{Notes and references}

1 M. Huang, R. Yu, K. Xu, S. Ye, S. Kuang, X. Zhu and Y. Wan, Chem. Sci., 2016, 7, 4485.

2 C. Z. Zhang, C. Lu, J. Zhu, G. Y. Lu, X. Wang, Z. W. Shi, F. Liu and Y. Cui, Chem. Mater., 2006, 18, 6091.

3 J. J. Kim, J. Lee, S. P. Yang, H. G. Kim, H. S. Kweon, S. Yoo and K. H. Jeong, Nano Lett., 2016, 16, 2994.

4 K. Jiang, L. Zhang, J. Lu, C. Xu, C. Cai and H. Lin, Angew. Chem., Int. Ed., 2016, 55, 7231.

5 B. E. Hardin, H. J. Snaith and M. D. McGeheem, Nat. Photonics, 2012, 6, 162.

6 A. Osuka and T. Tanaka, Chem. Soc. Rev., 2015, 44, 943.

7 R. Furue, T. Nishimoto, I. S. Park, J. Lee and T. Yasuda, Angew. Chem., Int. Ed., 2016, 55, 7171.

8 J. A. Davies, A. Langovan, P. A. Sullivan, B. C. D. H. Olbricht, T. R. Ewy, C. M. Isborn, B. E. Eichinger, B. H. Robinson, P. J. Reid, X. Li and L. R. Dalton, J. Am. Chem. Soc., 2008, 130, 10565.

9 G. Xie, D. Chen, X. Li, X. Cai, Y. Li, D. Chen, K. Liu, Q. Zhang, Y. Cao and S. J. Su, ACS Appl. Mater. Interfaces, 2016, 8, 27920.

10 S. R. Forrest and M. E. Thompson, Chem. Rev., 2007, 107, 923.

11 P. A. Sullivan and L. R. Dalton, Acc. Chem. Res., 2010, 43, 10. 12 L. Yan, X. Chen, Q. He, Y. Wang, X. Wang, Q. Guo, F. Bai, A. Xia, D. Aumiler, S. Vdović and S. Lin, J. Phys. Chem. A, 2012, 116, 8693.

13 C. Sissa, F. Terenziani, A. Painelli, R. Siram, K. Bhaskar and S. Patil, J. Phys. Chem. B, 2012, 116, 4959.

14 J. Z. Cheng, C. C. Lin, P. T. Chou, A. Chaskar and K. T. Wong, Tetrahedron, 2011, 67, 734.
15 E. Zojer, D. Beljonne, P. Pacher and J. L. Bredas, Chem.-Eur. J., 2004, 10, 2668.

16 P. Hrobárik, V. Hrobáriková, V. Semak, P. Kasák, E. Rakovský, I. Polyzos, M. Fakis and P. Persephonis, Org. Lett., 2014, 16, 6358.

17 B. D. Zhao, G. L. Li, Y. Z. Shi, H. Q. Zhang and T. Wang, RSC Adv., 2015, 5, 54749.

18 W. Hu, F. Bai, X. Gong, X. Zhan, H. Fu and T. Bjornholm, in Organic Optoelectronics, Wiley-VCH, Weinheim, Germany, 2013.

19 S. Kumar, P. Kumar, R. Srivastava, S. K. Pal and S. Ghosh, J. Phys. Chem. C, 2016, 120, 12723.

20 T. H. Huang, J. T. Lin, L. Y. Chen, Y. T. Lin and C. C. Wu, Adv. Mater., 2006, 18, 602.

21 S. L. Lin, L. H. Chan, R. H. Lee, M. Y. Yen, W. J. Kuo, C. T. Chen and R. J. Jeng, Adv. Mater., 2008, 20, 3947.

22 Y. Zhang, S. L. Lai, Q. X. Tong, M. F. Lo, T. W. Ng, M. Y. Chan, Z. C. Wen, J. He, K. S. Jeff, X. L. Tang, W. M. Liu, C. C. Ko, P. F. Wang and C. S. Lee, Chem. Mater., 2012, 24, 61.

23 Q. Zhang, J. Li, K. Shizu, S. Huang, S. Hirata, H. Miyazaki and C. Adachi, J. Am. Chem. Soc., 2012, 134, 14706.

24 T. Nakagawa, S. Y. Ku, K. T. Wong and C. Adachi, Chem. Commun., 2012, 48, 9580.

25 J. Ye, Z. Chen, M. K. Fung, C. Zheng, X. Ou, X. Zhang, Y. Yuan and C. S. Lee, Chem. Mater., 2013, 25, 2630.

26 L. Duan, J. Qiao, Y. Sun and Y. Qiu, Adv. Mater., 2011, 23, 1137.

27 A. R. Morales, A. Frazer, A. W. Woodward, H. Y. Ahn-White, A. Fonari, P. Tongwa, T. Timofeeva and K. D. Belfield, J. Org. Chem., 2013, 78, 1014.

28 M. Kivala and F. Diederich, Acc. Chem. Res., 2009, 42, 235.

29 J. S. Roncali, Chem. Rev., 1997, 97, 173.

30 H. Zhu, M. Li, J. Hu, X. Wang, J. Jie, Q. Guo, C. Chen and A. Xia, Sci. Rep., 2016, 6, 24313.

31 M. Monçalves, D. S. Rampon, P. H. Schneider, F. S. Rodembusch and C. C. Silveira, Dyes Pigm., 2014, 102, 71.

32 Q. Verolet, A. Rosspeintner, S. Soleimanpour, N. Sakai, E. Vauthey and S. Matile, J. Am. Chem. Soc., 2015, 137, 15644.

33 J. Míšek, A. V. Jentzsch, S. Sakurai, D. Emery, J. Mareda and S. Matile, Angew. Chem., Int. Ed., 2010, 49, 7680.

34 S. O. Jeon, T. Earmme and S. A. Jenekhe, J. Mater. Chem. C, 2014, 2, 10129.

35 M. Wang, X. Ma, J. Yu, X. Jia, D. Han, T. Zhou, J. Yang, J. Nie and T. Wang, Polym. Chem., 2015, 6, 4424.

36 C. Nerungsi, P. Wanitchang, S. Sahasithiwat, K. Sadorn, T. Kerdcharoen and T. Thongpanchang, Tetrahedron Lett., 2010, 51, 6392.

37 S. Malashikhin and N. S. Finney, J. Am. Chem. Soc., 2008, 130, 12846.

38 T. H. Lee, K. L. Tong, S. K. So and L. M. Leung, Synth. Met., 2005, 155, 116.

39 C. C. Silveira, F. Rinaldi and R. C. Guadagnin, Eur. J. Org. Chem., 2007, 4935.

40 G. Padilha, T. S. Kaufman and C. C. Silveira, Tetrahedron Lett., 2016, 57, 3349. 
41 M. M. Bassaco, M. Monçalves, F. Rinaldi, T. S. Kaufman and C. C. Silveira, J. Photochem. Photobiol., A, 2014, 290, 1.

42 W. L. F. Armarego, in Purification of Laboratory Chemicals, ed. W. L. F. Armarego and C. L. L. Chai, fifth edn, Elsevier Academic Press, Cornwall, UK, 2003.

43 J. N. Demas and G. A. Crosby, J. Phys. Chem., 1971, 75, 991. 44 M. J. Frisch, G. W. Trucks, H. B. Schlegel, G. E. Scuseria, M. A. Robb, J. R. Cheeseman, G. Scalmani, V. Barone, B. Mennucci, G. A. Petersson, H. Nakatsuji, M. Caricato, X. Li, H. P. Hratchian, A. F. Izmaylov, J. Bloino, G. Zheng, J. L. Sonnenberg, M. Hada, M. Ehara, K. Toyota, R. Fukuda, J. Hasegawa, M. Ishida, T. Nakajima, Y. Honda, O. Kitao, H. Nakai, T. Vreven, J. A. Montgomery Jr, J. E. Peralta, F. Ogliaro, M. Bearpark, J. J. Heyd, E. Brothers, K. N. Kudin, V. N. Staroverov, T. Keith, R. Kobayashi, J. Normand, K. Raghavachari, A. Rendell, J. C. Burant, S. S. Iyengar, J. Tomasi, M. Cossi, N. Rega, J. M. Millam, M. Klene, J. E. Knox, J. B. Cross, V. Bakken, C. Adamo, J. Jaramillo, R. Gomperts, R. E. Stratmann, O. Yazyev, A. J. Austin, R. Cammi, C. Pomelli, J. W. Ochterski, R. L. Martin, K. Morokuma, V. G. Zakrzewski, G. A. Voth, P. Salvador, J. J. Dannenberg, S. Dapprich, A. D. Daniels, O. Farkas, J. B. Foresman, J. V. Ortiz, J. Cioslowski, and D. J. Fox, Gaussian 09, Revision D.01,Gaussian, Inc., Wallingford CT, USA, 2013.

45 C. Adamo and V. Barone, J. Chem. Phys., 1999, 110, 6158.

46 T. Yanai, D. Tew and N. Handy, Chem. Phys. Lett., 2004, 393, 51.

47 D. M. P. Aroche, J. M. Toldo, R. R. Descalzo, P. F. B. Gonçalves and F. S. Rodembusch, New J. Chem., 2015, 39, 6987.

48 C. Adamo and D. Jacquemin, Chem. Soc. Rev., 2013, 42, 845.

49 M. Pastore, E. Mosconi, F. Angelis and M. Grätzel, J. Phys. Chem. C, 2010, 114, 7205.

50 A. D. Laurent and D. Jacquemin, Int. J. Quantum Chem., 2013, 113, 2019.

51 E. Papajak, J. Zheng, H. R. Leverentz and D. G. Truhlar, J. Chem. Theory Comput., 2011, 7, 3027.

52 J. Tomasi, B. Mennucci and R. Cammi, Chem. Rev., 2005, 105, 2999.
53 G. A. Andrienko, CHEMCRAFT, http:// www.chemcraftprog.com.

54 K. Otrubova, B. F. Cravatt and D. L. Boger, J. Med. Chem., 2014, 57, 1079.

55 S. J. Strickler and R. A. Berg, J. Phys. Chem., 1962, 37, 814.

56 N. J. Turro, J. C. Scaiano and V. Ramamurthy, in Principles of Molecular Photochemistry: An Introduction, University Science Books, Sausalito, USA, 1st edn, 2008.

57 J. R. Lakowicz, in Principles of Fluorescence Spectroscopy, Springer, New York, 3rd edn, 2006, ch. 6, pp. 205-235.

58 S. Achelle, A. Barsella, B. Caro and F. R. Guen, RSC Adv., 2015, 5, 39218.

59 B. Huang, Q. Qi, W. Jiang, J. Tang, Y. Liu, W. Fan, Z. Yin, F. Shi, X. Ban, H. Xu and Y. Sun, Dyes Pigm., 2014, 111, 135.

60 B. Huang, Z. Yin, X. Ban, Z. Ma, W. Jiang, W. Tian, M. Yang, S. Ye, B. Lin and S. Yueming, J. Lumin., 2016, 172, 7.

61 R. S. Kathayat and N. S. Finney, J. Am. Chem. Soc., 2013, 135, 12612.

62 W. Lee and W. S. Jenks, J. Org. Chem., 2001, 66, 474.

63 S. A. El-Daly, A. M. Asiri and K. A. Alamry, J. Fluoresc., 2014, 24, 1307.

64 E. Lippert, W. Lüder, F. Moll, W. Nägele, H. Boos, H. Prigge and I. Seinbold-Blankenstein, Angew. Chem., 1961, 73, 695.

65 J. P. Cerón-Carrasco, A. Ripoche, F. Odobel and D. Jacquemin, Dyes Pigm., 2012, 92, 1144.

66 H. Roohi, F. Hejazi, N. Mohtamedifar and M. Jahantab, Spectrochim. Acta, Part A, 2014, 118, 228.

67 R. S. Iglesias, L. F. Campo, F. S. Rodembusch and V. Stefani, Int. J. Quantum Chem., 2008, 108, 2334.

68 M. Liang and J. Chen, Chem. Soc. Rev., 2013, 42, 3453.

69 S. Agrawal, N. J. English, K. R. Thampi and J. M. MacElroy, Phys. Chem. Chem. Phys., 2012, 14, 12044.

70 Z. R. Grabowski and K. Rotkiewicz, Chem. Rev., 2003, 103, 3899.

71 C. Bernini, J. Chem. Theory Comput., 2014, 10, 3925.

72 C. A. Guido, P. Cortona, B. Mennucci and C. Adamo, J. Chem. Theory Comput., 2013, 9, 3118.

73 T. Lu and F. Chen, J. Comput. Chem., 2012, 33, 580. 